\title{
Considerations for the management of colorectal cancer during the Covid-19 pandemic
}

\author{
Considerações para o gerenciamento do câncer coloretal durante a pandemia de Covid-19
}

Carlos Augusto Rodrigues Véo ${ }^{1} \odot$, Maximiliano Cadamuro Neto ${ }^{2}{ }^{\circ}$, Gilmar Espírito Santo ${ }^{3} \odot$, Rafael Oliveira de Souza ${ }^{4} \odot$, Daniel Cesar ${ }^{5} \odot$, Paulo Henrique de Sousa Fernandes ${ }^{6} \odot$, Reitan Ribeiro ${ }^{7}$, Heber Salvador de Castro Ribeiro ${ }^{8} \odot$, Alexandre Ferreira Oliveira ${ }^{9} \odot$

\begin{abstract}
The number of people infected with the coronavirus (COVID-19) is increasing rapidly in Brazil. It has been proven that COVID-19 can be transmitted from human to human and can lead to hospital-acquired infections, which seriously threaten surgical teams and inpatients. We emphasize that the following suggestions are based on minimal worldwide experience in coping with the disease and are in line with similar attempts to recognize better therapies. Thus, these recommendations can be modified.
\end{abstract}

Keywords: Colorectal Neoplasms. Coronavirus Infections. Pandemics.

\begin{abstract}
RESUMO
O número de pessoas infectadas com o coronavírus (COVID-19) está aumentando rapidamente no Brasil. Está provado que o COVID-19 pode ser transmitido de humano para humano e pode levar a infecções adquiridas em hospitais, que ameaçam seriamente as equipes cirúrgicas e pacientes internados.

Enfatizamos que as sugestões a seguir são baseadas em uma experiência mundial mínima no enfrentamento da doença e estão alinhadas com tentativas semelhantes de reconhecer melhores terapias. Assim, essas recomendações podem ser modificadas.
\end{abstract}

Descritores: Colorectal Neoplasms. Coronavirus Infections. Pandemics.

1. Barretos Câncer Hospital, Colorectal oncosurgery department - Barretos - São Paulo - Brazil.

2. Barretos Câncer Hospital, Colorectal oncosurgery department - Barretos - São Paulo - Brazil.

3. Institute of Tumors of Cuiabá - General Hospital/ University of Cuiabá, Department of surgery - Cuiabá - Mato Grosso - Brazil.

4. Cancer Treatment Institute - Santa Casa - Campo Grande, Department of surgery - Campo Grande - Mato Grosso do Sul - Brazil.

5. National Cancer Institute, Department of oncologic surgery - Rio de Janeiro - Rio de Janeiro - Brazil.

6. Federal University of Uberlândia, Department of Sugical Oncology - Uberlândia - Minas Gerais - Brazil.

7. Erasto Gaertner Hospital, Department of Sugical Oncology - Curitiba - Paraná - Brazil.

8. AC Camargo Cancer Center, Department of Abdominal Surgery - São Paulo - São Paulo - Brazil.

9. Federal University of Juiz de Fora - UFJF, Department of Surgical - Juiz de Fora - Minas Gerais - Brazil.

Financial support: none to declare.

Conflicts of interest: The authors declare no conflict of interest relevant to this manuscript.

Correspondence author: Carlos Augusto Rodrigues Véo, Barretos Câncer Hospital, Colorectal oncosurgery department - Barretos - São Paulo - Brazil. R. Antenor Duarte Viléla, 1331 - Dr. Paulo Prata, Barretos - SP, 14784-400.

E-mail: cveodriveo@gmail.com / cveo@uol.com.br 


\section{CONSIDERATIONS FOR THE MANAGEMENT OF COLORECTAL CANCER DURING THE COVID-19 PANDEMIC}

The number of people infected with the coronavirus (COVID-19) is increasing rapidly in Brazil. It has been proven that COVID-19 can be transmitted from human to human and can lead to hospital-acquired infections, which seriously threaten surgical teams and inpatients.

Cancer patients are more susceptible to infection and the presence of a tumor is defined as an important factor of poor prognosis, making this a challenge for doctors and patients. This obviously applies to colorectal cancer so we will suggest some approaches based on measures adopted by countries that have already faced the pandemic or have been fighting it longer than Brazil, pursuant to the guidelines of the Ministry of Health and the actions implemented in our hospitals.

All decisions and recommendations that we make as oncologists involve an analysis of the risk-benefit ratio of each specific patient. Amidst the current pandemic, while the benefits of cancer therapies remain the same, the risks have increased substantially, requiring careful reconsideration of many of our practices. The risk-benefit ratio now needs to be reconsidered for individual patients based on disease status, age, frailty and comorbidities.

The responsibility for decision-making to carry out or postpone surgery or other treatment should be shared with the patient and their family members, using the consent form and noting the conduct in the medical record.

We emphasize that the following suggestions are based on minimal worldwide experience in coping with the disease and are in line with similar attempts to recognize better therapies. Thus, these recommendations can be modified.

\section{We suggest that benign elective surgeries be} postponed:

- gastrointestinal tract reconstructions

- incisional hernia repairs

- colectomies to treat familial adenomatous polyposis

- among others

\section{Catheter implants for chemotherapy}

- should be performed if the chemotherapy treatment cannot be postponed or replaced by an oral medication, without harm to patients

- $\quad$ the frequency of visits for care (heparinization) of central venous access catheters should be extended to at least 12 weeks, due to insufficient evidence that more frequent visits are necessary. For patients not in active therapy, the risk of exposure to coronavirus may outweigh the benefit of more frequent catheter care
Urgent and emergency procedures must be performed:

- Intestinal obstructions should be operated on if they are unresponsive to clinical treatment or radiation therapy in the case of partially obstructive tumors. For services with endoscopic prosthesis placement, this measure should be considered

- $\quad$ severe acute gastrointestinal bleeding, which required transfusion or caused hemodynamic instability. Where possible, hemostatic radiotherapy or embolization therapy may be considered

- gastrointestinal perforations

- $\quad$ peritonitis

- cases of acute abdomen due to localized collections that are not possible to treat via image-guided puncture or are unresponsive to clinical treatment

\section{Stage I and II colorectal tumors:}

Without the aforementioned urgency or emergency criteria, patients with asymptomatic or minimally symptomatic tumors could have their treatments postponed for 30 to 60 days, as long as there is no evidence to the contrary, taking into account the biology of the tumor, other treatment options, and the institution's policy in each moment of the pandemic. If you have a coronavirus-free center to treat cancer patients, you should consider performing surgical procedures.

\section{Stage III colorectal tumors:}

For resectable colon cancer that is locally advanced (cT4b) and with low probability of failure in staging by imaging, and cancer of the mid and low rectum (cT3-4 or $\mathrm{N}+$ ), planning for neoadjuvant therapy can be carried out after multidisciplinary discussion.

- for cT4b colon cancer, 2 to 3 courses (42 - 63 days) of neoadjuvant chemotherapy (CapeOx) can be recommended.

- Patients with non-metastatic colon cancer who are candidates for curative surgery should be operated if we believe that the delay in surgery will compromise the cure, especially in hospitals without COVID-19 or with very low occurrence

- for cancer of the rectum cT3-4 or N+, neoadjuvant therapy with short-course radiotherapy may be indicated, with the benefit of fewer patients coming to the hospital, decreasing the risk of contamination. Conventional radiotherapy with chemotherapy would be reserved for cases in which a maximum objective response is needed, such as for preservation of the sphincter or for tumors invading structures

- $\quad$ surgery for rectal cancer should be performed within 8 to 12 weeks after the end of neoadjuvant radiotherapy, and the surgery may be postponed up to 16 weeks if downstaging was observed, depending on the need due to the risk and availability of beds 
- in the case that surgery is impossible to perform, consider additional systemic chemotherapy according to risk versus benefit and after multidisciplinary discussion

- one can also consider full neoadjuvant treatment, in the absence of surgery at the desired time

- the watch-and-wait strategy in rectal tumor treatment can be considered, provided that all the criteria published in the referral and follow-up of these patients are respected, including the strict criteria for considering a complete response. It should be explained to the patient that, at the moment, this procedure is not considered the gold standard.

- Four cycles of neoadjuvant mFOLFOX6 alone may be an option for neoadjuvant therapy in selected cases upon a multidisciplinary discussion

\section{Stage IV metastatic colorectal tumors:}

- for resectable tumors, chemotherapy can be administered for 2 to 3 courses, and the surgery scheduled following the last cycle

- for unresectable disease, translational therapy with chemotherapy and targeted drugs can be considered.

* Complex surgeries or surgeries that are outside the guidelines' recommendations should be avoided at this time.

* The possibility of local resection of small tumors in the rectum should be evaluated using transanal endoscopic microsurgery (TEM / TEO / TAMIS), which allow for faster recovery and discharge of the patient. The patient should be tested, if possible, and personal protective equipment used and staff in the room protected due to use of $\mathrm{CO} 2$ insufflation, which would increase the risk of contamination.

* Tumors in the anal canal should be evaluated for the possibility of undergoing exclusive treatment with radiotherapy and chemotherapy.

* Perform biopsies only when absolutely necessary for making clinical decisions that cannot wait until the end of the expected peak of the pandemic.

* For video laparoscopic surgeries:

- do not perform the procedure by laparoscopy in patients who tested positive or with high suspicion of COVID 19.

- For patients that test negative or that don't have any signs or symptoms of COVID-19, the procedure can be performed, if it is deemed that laparoscopy will be beneficial for the patient.

- take appropriate care to reduce the risk of contamination of the environment and the room personnel by using filters (rarely available), emptying the pneumoperitoneum slowly, and partially occluding the gas exit with a compress, or through some closed smoke evacuation system, and only make an incision to remove the surgical specimen after the pneumoperitoneum is completely empty. Do not use devices such as hand assisted devices and wound protectors that normally allow $\mathrm{CO} 2$ to escape into the surgical environment, increasing the risk of aerosol infection.

\section{AUTHOR'S CONTRIBUTION}

Carlos Augusto Rodrigues Véo: Collection and assembly of data, Conception and design, Data analysis and interpretation, Final approval of manuscript, Manuscript writing, Provision of study materials or patient.

Maximiliano Cadamuro Neto: Collection and assembly of data, Conception and design, Data analysis and interpretation, Final approval of manuscript, Manuscript writing, Provision of study materials or patient

Gilmar Espírito Santo: Collection and assembly of data, Conception and design, Data analysis and interpretation, Final approval of manuscript, Manuscript writing, Provision of study materials or patient.

Rafael Oliveira de Souza: Collection and assembly of data, Conception and design, Data analysis and interpretation, Final approval of manuscript, Manuscript writing, Provision of study materials or patient.
Daniel Cesar: Collection and assembly of data, Conception and design, Data analysis and interpretation,

Paulo Henrique de Sousa Fernandes: Collection and assembly of data, Conception and design, Data analysis and interpretation, Final approval of manuscript, Manuscript writing, Provision of study materials or patient.

Reitan Ribeiro: Collection and assembly of data, Conception and design, Data analysis and interpretation, Final approval of manuscript, Manuscript writing, Provision of study materials or patient.

Heber Salvador de Castro Ribeiro: Collection and assembly of data, Conception and design, Data analysis and interpretation, Final approval of manuscript, Manuscript writing, Provision of study materials or patient.

Alexandre Ferreira Oliveira: Collection and assembly of data, Conception and design, Data analysis and interpretation, Final approval of manuscript, Manuscript writing, Provision of study materials or patient. 